\title{
Acromegalic arthropathy
}

\author{
R. BLUESTONE*, E. G. L. BYWATERS, M. HARTOG, P. J. L. HOLT, AND \\ S. HYDE \\ From the Department of Medicine, Royal Postgraduate Medical School, London
}

\section{Introduction}

Spinal and peripheral joint abnormalities in patients with acromegaly, which have been recognized since the original description was published by Marie (1886), may be severely disabling. However, the nature of the arthropathy. is not clear, and only very limited morphological information is available (Erdheim, 1931; Waine, Bennett, and Bauer, 1945; Kellgren, Ball, and Tutton, 1952). Furthermore, present day pituitary gland ablation, together with more accurate assessment of treatment, should allow the reversibility of the arthropathy to be gauged.

We have systematically characterized the locomotor system disorders in a group of patients with acromegaly. Detailed studies of joint morphology have been undertaken in three patients; and we have correlated the arthropathy with the duration and severity of the acromegaly.

\section{Patients studied and methods}

A series of 42 consecutive patients admitted to hospital for assessment and treatment of adult-onset acromegaly was studied. There were 25 men (age range 22 to 66 years: mean 46) and 17 women (age range 26 to 68 years: mean 49). The approximate duration, severity, and activity of their pituitary disease was assessed in all but two patients. This assessment (by MH) was based on the clinical state, $x$-ray changes, and plasma growth hormone levels.

All patients were directly questioned about symptoms referable to their joints. Peripheral joints were examined, and total spinal movement was measured as the difference in centimetres between the 7th cervical vertebral spine and the sacro-coccygeal junction when the spine and hip were fully flexed and fully extended. Overall spine and hip mobility was assessed by measuring the minimum distance $(\mathrm{cm}$.) between the outstretched finger-tips and the floor in the straight-leg, bent-forward position ('fingerfloor distance'). Contact with the floor was recorded as zero and the amount of digital contact with the floor beyond zero was recorded as a minus value. As controls, total spinal movement and overall mobility was measured in ninety unselected hospital patients of both sexes and comparable age-range. $X$ rays were obtained of the peripheral joints and of the total spines in most patients.

\section{Results (Table, overleaf)}

\section{PERIPHERAL JOINTS}

Sixteen patients ( 9 men and 7 women) gave a history of intermittent and long-lasting pain with episodes lasting weeks or months, usually of the shoulders, knees, hands, or hips, but generalized in five and associated with widespread morning stiffness in two.

Peripheral joint abnormalities were detected in 26 patients of both sexes and all age groups. Joint swelling, other than simple bone-end enlargement, was found in nine patients. This was usually a painful knee swelling, sometimes due to effusion but more usually thickened synovial or periarticular structures. A prominent prepatellar bursa was a common finding. Painless swelling of proximal interphalangeal, metacarpophalangeal, or carpometacarpal joints was also noted, and a dorsal expansion of the bases of the middle phalanges (producing a bony ridge just distal to the proximal interphalangeal joints) was present in twelve patients. Painful limitation of joint movement was found in eight patients, being generalized in three and particularly affecting the shoulders. Significant coarse crepitus throughout the full range of joint movement was detected in over half the patients. It was most marked in the knees and shoulders but was usually symptomless.

A history characteristic of carpal tunnel syndrome was given by 22 patients, bilateral in all but two, but without noticeable wasting of the hand muscles Ten patients described symptons suggestive of mild Raynaud's phenomenon.

\section{SPINE}

Twenty patients (12 men and 8 women) gave a history of non-traumatic backache, usually of the lumbo-sacral spine but occasionally involving the thoracic and cervical spine.

Mean total spinal movement was not significantly 
Table Acromegaly: clinical and radiological findings in locomotor system in 42 cases

\begin{tabular}{|c|c|c|c|c|c|c|c|c|c|c|c|}
\hline \multirow[t]{2}{*}{$\begin{array}{l}\text { Patient } \\
\text { no. }\end{array}$} & \multirow[t]{2}{*}{$\begin{array}{l}\text { Age } \\
\text { (yrs) }\end{array}$} & \multirow[t]{2}{*}{ Sex } & \multirow{2}{*}{$\begin{array}{l}\text { Duration } \\
\text { of } \\
\text { disease* }\end{array}$} & \multirow{2}{*}{$\begin{array}{l}\text { Severity } \\
\text { of } \\
\text { disease }\end{array}$} & \multirow{2}{*}{$\begin{array}{l}\text { Carpal } \\
\text { tunnel } \\
\text { syndrome }\end{array}$} & \multicolumn{6}{|c|}{$\begin{array}{l}\text { Peripheral joint } \\
\text { swelling and/or limitation }\end{array}$} \\
\hline & & & & & & $\boldsymbol{H}$ & $\boldsymbol{K}$ & $\boldsymbol{A}$ & $\boldsymbol{S}$ & $E$ & $\boldsymbol{H a}$ \\
\hline $\begin{array}{l}1 \\
2 \\
3 \\
4 \\
5 \\
6 \\
7 \\
8 \\
9 \\
10 \\
11 \\
12 \\
13 \\
14 \\
15 \\
16 \\
17 \\
18 \\
19 \\
20 \\
21 \\
22 \\
23 \\
24 \\
25 \\
26 \\
27 \\
28 \\
29 \\
30 \\
31 \\
32 \\
33 \\
34 \\
35 \\
36 \\
37 \\
38 \\
39 \\
40 \\
41 \\
42\end{array}$ & $\begin{array}{l}26 \\
40 \\
47 \\
58 \\
26 \\
28 \\
42 \\
57 \\
62 \\
66 \\
51 \\
34 \\
44 \\
55 \\
46 \\
53 \\
35 \\
51 \\
61 \\
35 \\
60 \\
67 \\
68 \\
40 \\
42 \\
60 \\
51 \\
51 \\
22 \\
41 \\
45 \\
48 \\
58 \\
43 \\
58 \\
24 \\
34 \\
35 \\
44 \\
64 \\
59 \\
47\end{array}$ & $\begin{array}{l}\mathbf{M} \\
\mathbf{F} \\
\mathbf{F} \\
\mathbf{M} \\
\mathbf{F} \\
\mathbf{M} \\
\mathbf{M} \\
\mathbf{F} \\
\mathbf{F} \\
\mathbf{M} \\
\mathbf{M} \\
\mathbf{M} \\
\mathbf{F} \\
\mathbf{F} \\
\mathbf{M} \\
\mathbf{M} \\
\mathbf{M} \\
\mathbf{M} \\
\mathbf{M} \\
\mathbf{F} \\
\mathbf{F} \\
\mathbf{F} \\
\mathbf{F} \\
\mathbf{M} \\
\mathbf{M} \\
\mathbf{M} \\
\mathbf{M} \\
\mathbf{F} \\
\mathbf{M} \\
\mathbf{M} \\
\mathbf{M} \\
\mathbf{M} \\
\mathbf{M} \\
\mathbf{F} \\
\mathbf{F} \\
\mathbf{M} \\
\mathbf{M} \\
\mathbf{F} \\
\mathbf{F} \\
\mathbf{M} \\
\mathbf{M} \\
\mathbf{F}\end{array}$ & 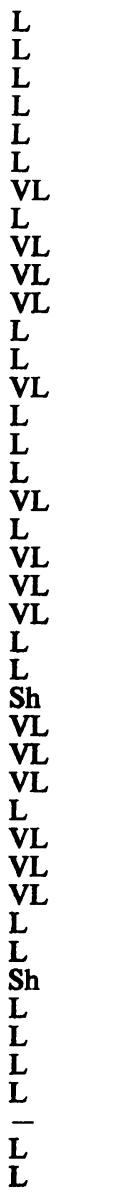 & 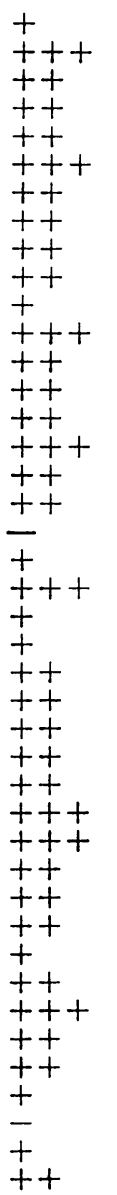 & $\begin{array}{l}+ \\
+ \\
+ \\
+ \\
+ \\
+ \\
+ \\
+ \\
+ \\
+ \\
+ \\
+\end{array}$ & $\begin{array}{l}* \\
* \\
*\end{array}$ & $\begin{array}{l}* \\
* \\
* \\
* \\
* \\
*\end{array}$ & * & $\begin{array}{l}\text { * } \\
* \\
* \\
* \\
* \\
*\end{array}$ & $\begin{array}{l} \\
* \\
*\end{array}$ & * \\
\hline
\end{tabular}

Duration: VL $=$ very long; $L=$ long; Sh $=$ short; $-=$ not recorded.

Joints: $\mathbf{H}=$ hip; $K=$ knee; $\mathbf{A}=$ ankle; $\mathbf{S}=$ shoulder; $\mathbf{E}=$ olbow; $H a=$ hands.

Severity of disease, backache, and $x$-ray changes classified as severe +++ ; moderate ++ ; mild + .

reduced in the patient group $(15 \cdot 3 \mathrm{~cm}$.) as compared to the control subjects $(16 \cdot 3 \mathrm{~cm}$.), regardless of the presence or absence of backache (Fig. 1).

Mean overall spine and hip mobility (measured as finger-floor distance) was $3 \cdot 2 \mathrm{~cm}$. for the patients compared to $6.8 \mathrm{~cm}$. for the controls $(P=<0.01)$, suggesting increased mobility in patients with acromegaly (Fig. 2). This was particularly marked in some older patients, despite backache.

\section{RADIOLOGY}

Hands

The main features were the well-recognized increased cartilage thickness and the heavy ungual tufting. Other changes included extension of joint margins to form bony lips especially at the bases of terminal phalanges, resulting in sclerotic-looking hooks. Associated with this were small round areas of joint capsule calcification or ossification at the middle and terminal interphalangeal joints, present in nearly half of the films examined (Fig. $3 a$, overleaf).

Metacarpal head exostoses at the sites of ligament attachment led to squaring of the bone ends. Remodelling of the phalanges leading to loss of the waists in the distal parts of the shafts was always present (Fig. 4, overleaf). Sesamoid bones over flexor surfaces of joints were large and prominent, particularly over the first metacarpophalangeal joint. The joint surfaces were smooth, without sclerosis, erosions, or malalignment. 


\begin{tabular}{|c|c|c|c|c|c|c|c|c|}
\hline \multicolumn{3}{|c|}{$\begin{array}{l}\text { Joints affected } \\
\text { by crepitus }\end{array}$} & \multicolumn{2}{|c|}{$\begin{array}{l}\text { Spinal movement } \\
(\mathrm{cm} .)\end{array}$} & \multirow[t]{2}{*}{ Backache } & \multicolumn{3}{|c|}{ Spinal $\mathrm{x}$-ray changes } \\
\hline $\boldsymbol{K}$ & $A$ & $S$ & Finger-floor & Total & & Cervical & Thoracic & Lumbar \\
\hline & * & & -18 & $25 \cdot 5$ & + & & & \\
\hline * & $*$ & * & $\begin{array}{r}-11 \cdot 5 \\
-6 \cdot 5\end{array}$ & $\begin{array}{l}25 \cdot 5 \\
24\end{array}$ & ++ & - & & + \\
\hline * & & & $-12 \cdot 5$ & $21 \cdot 5$ & & - & ++ & $+t$ \\
\hline * & & & $\begin{array}{r}10 \\
-4\end{array}$ & $\begin{array}{l}20 \cdot 5 \\
20 \cdot 5\end{array}$ & $\begin{array}{l}++ \\
+\end{array}$ & + & + & \\
\hline$*$ & * & & $-7 \cdot 5$ & $20 \cdot 5$ & & $\stackrel{+}{+}$ & $\stackrel{+}{+}$ & $\bar{t}++$ \\
\hline$*$ & & * & -9 & 19 & + & - & - & \\
\hline * & * & & $-20 \cdot 5$ & 19 & ++ & - & - & - \\
\hline * & * & * & $\begin{array}{r}5 \\
15\end{array}$ & 15 & + & - & + & ++ \\
\hline$*$ & ${ }^{*}$ & & $\begin{array}{l}15 \\
15\end{array}$ & $\begin{array}{l}12 \cdot 5 \\
11 \cdot 5\end{array}$ & $\begin{array}{l}+ \\
+\end{array}$ & $\bar{z}$ & + & $\begin{array}{l}+t+ \\
+\end{array}$ \\
\hline * & & * & -5 & $11 \cdot 5$ & + & & ++ & \\
\hline * & & * & $-7 \cdot 5$ & $11 \cdot 5$ & + & + & ++ & \\
\hline * & & $*$ & $16 \cdot 5$ & $12 \cdot 5$ & + & & +++ & + \\
\hline * & & & 二 & $\bar{z}$ & + & - & ++ & ++ \\
\hline * & & * & - & - & ++ & - & +++ & + \\
\hline * & & * & $\underline{0}$ & 二 & + & - & 一 & 一 \\
\hline$*$ & $*$ & $*$ & $-\overline{18}$ & 23 & + & & ++ & + \\
\hline * & & & $\underline{6 \cdot 5}$ & $12 \cdot 5$ & & & + & \\
\hline * & $*$ & & $-\overline{15}$ & $\overline{15}$ & & & & + \\
\hline * & & * & $\overline{0}$ & $\overline{19}$ & & + & $++t$ & \\
\hline * & & * & $-12 \cdot 5$ & $\begin{array}{l}19 \\
18\end{array}$ & & \pm & $\stackrel{+t}{t}$ & $\begin{array}{l}++ \\
+\end{array}$ \\
\hline * & & * & 4 & 12 & & - & ++ & $\dot{t}$ \\
\hline * & & $\begin{array}{l}* \\
*\end{array}$ & $-7 \cdot 5$ & $25 \cdot 5$ & & - & & \\
\hline * & $*$ & $*$ & 10 & 15 & & - & ++ & \\
\hline & & * & $\underline{4}$ & 14 & & - & + & $+t$ \\
\hline$*$ & & & $\overline{7}$ & - & & - & ++ & ++ \\
\hline * & & & $\begin{array}{r}-7 \cdot 5 \\
-20 \cdot 5\end{array}$ & $\overline{15}$ & & & $\underset{+}{+}+$ & ++ \\
\hline & & & $\begin{array}{c}6 \cdot 5 \\
14\end{array}$ & $\begin{array}{l}14 \cdot 5 \\
16\end{array}$ & & & & \\
\hline & & & - & - & & - & + & $++t$ \\
\hline & & & - & - & & - & +++ & +++ \\
\hline & & & $\overline{24}$ & $\overline{11} \cdot 5$ & & $\bar{z}$ & $\begin{array}{l}++ \\
+\end{array}$ & $+t$ \\
\hline
\end{tabular}
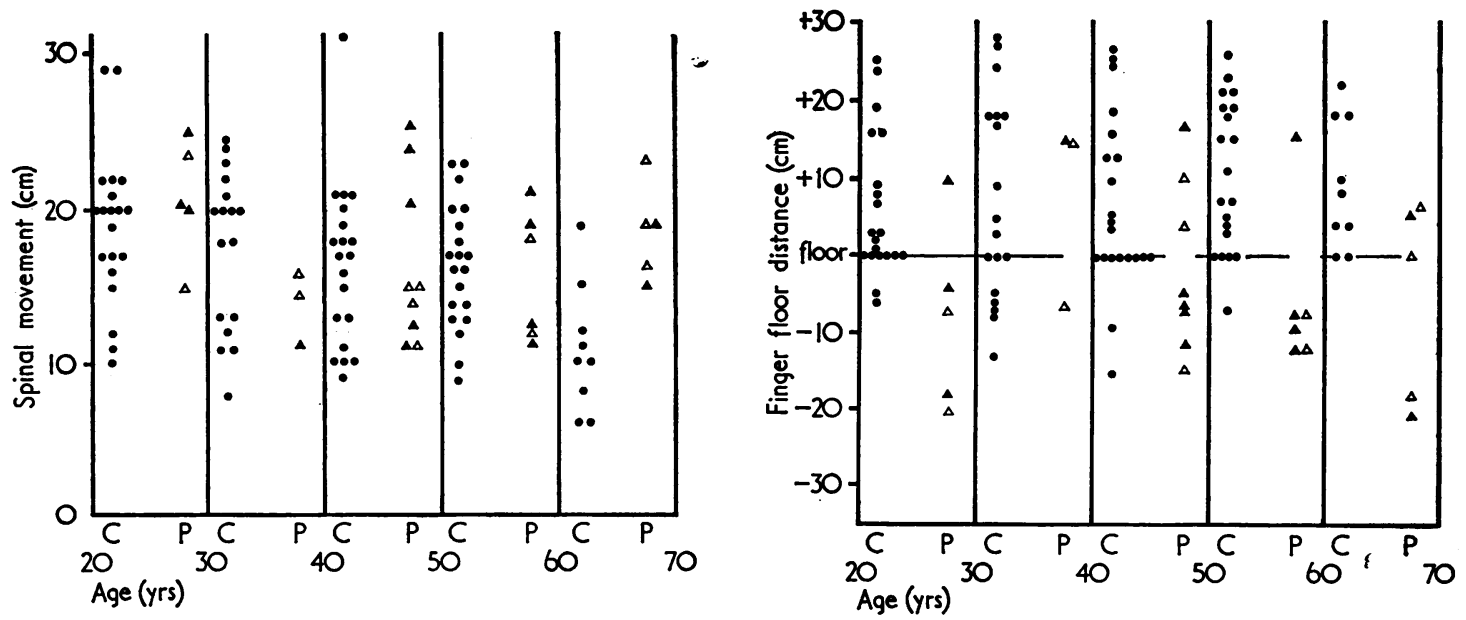

fIG. 2 Finger-floor distance (see text).

FIG. 1 Spinal movement (see text)

$C=$ Control subjects; $P=$ Patients; $\Delta=$ Patients with backache; $\Delta=$ Patients without backache. No sex difference detected. 

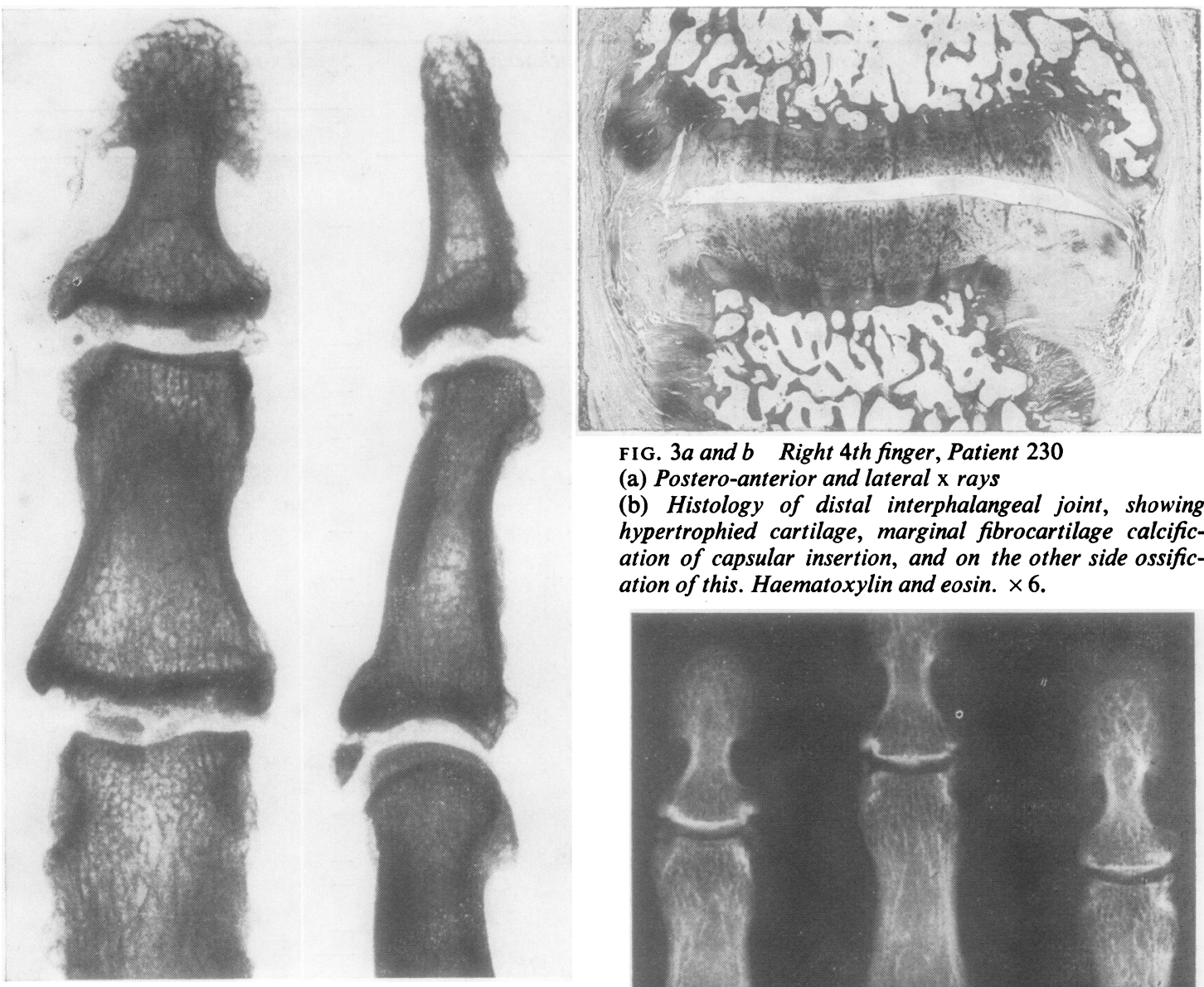

FIG. $3 a$ and $b \quad$ Right 4 th finger, Patient 230

(a) Postero-anterior and lateral $\mathrm{x}$ rays

(b) Histology of distal interphalangeal joint, showing hypertrophied cartilage, marginal fibrocartilage calcification of capsular insertion, and on the other side ossification of this. Haematoxylin and eosin. $\times 6$.

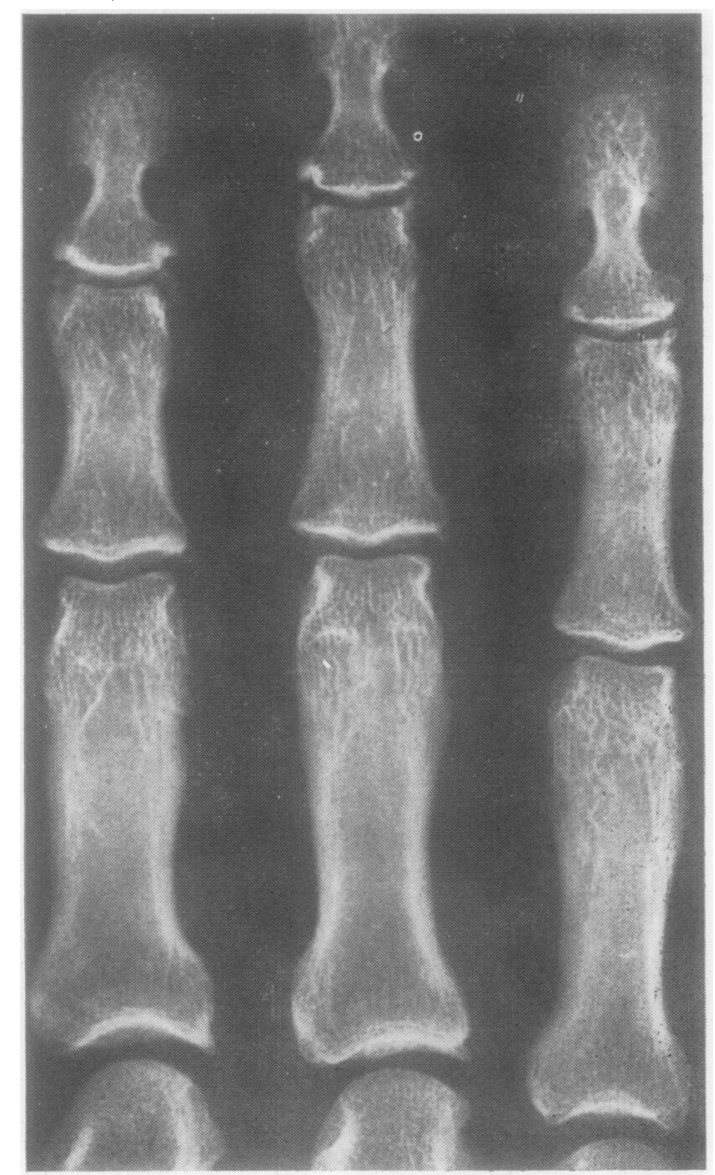

\section{Knees}

Unusually wide joint spaces, indicative of thickened cartilage, were common both between the tibia and femur and behind the patellar. Some patients had osteophytosis of the joint margins and intracondylar notch. Cartilage calcification, resembling chondrocalcinosis, was noted in several patients but was never gross. More discrete areas of capsular ossification, some having the appearance of intra-articular foreign bodies, were also seen.

\section{Hips}

Widened cartilage spaces were prominent. The formation of a lip at the external acetabular margin was frequent and sometimes extensive. Only one patient had definite radiological evidence of bilateral osteoarthrosis (Fig. 5). In this patient cartilage loss was accompanied by irregularity and sclerosis of subchondral bone with cyst formation; the medial joint compartments were filled with new bone. Another patient showed gross acetabular osteophytes but had retained cartilage.

FIG. $4 \mathrm{X}$ ray of right 2 nd, 3rd, and 4th phalanges, Patient 14, showing capsular ossification of terminal interphalangeal joints and rarrodelling of proximal phalangeal shafts. 

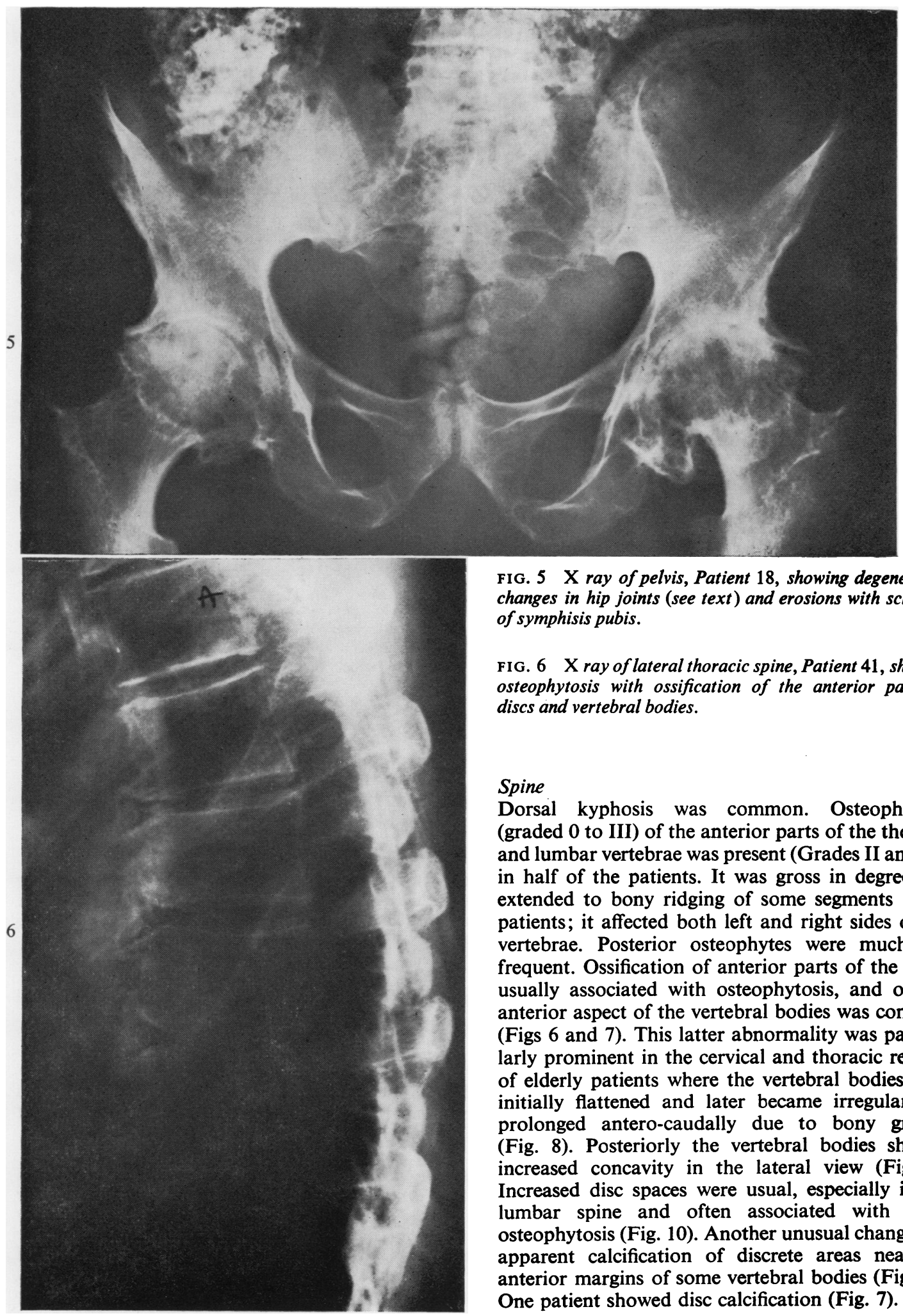

FIG. $5 \mathrm{X}$ ray of pelvis, Patient 18, showing degenerative changes in hip joints (see text) and erosions with sclerosis of symphisis pubis.

FIG. 6 X ray of lateral thoracic spine, Patient 41, showing osteophytosis with ossification of the anterior parts of discs and vertebral bodies.

\section{Spine}

Dorsal kyphosis was common. Osteophytosis (graded 0 to III) of the anterior parts of the thoracic and lumbar vertebrae was present (Grades II and III) in half of the patients. It was gross in degree and extended to bony ridging of some segments in six patients; it affected both left and right sides of the vertebrae. Posterior osteophytes were much less frequent. Ossification of anterior parts of the discs, usually associated with osteophytosis, and on the anterior aspect of the vertebral bodies was common (Figs 6 and 7). This latter abnormality was particularly prominent in the cervical and thoracic regions of elderly patients where the vertebral bodies were initially flattened and later became irregular and prolonged antero-caudally due to bony growth (Fig. 8). Posteriorly the vertebral bodies showed increased concavity in the lateral view (Fig. 9). Increased disc spaces were usual, especially in the lumbar spine and often associated with gross osteophytosis (Fig. 10). Another unusual change was apparent calcification of discrete areas near the anterior margins of some vertebral bodies (Fig. 11). One patient showed disc calcification (Fig. 7). 


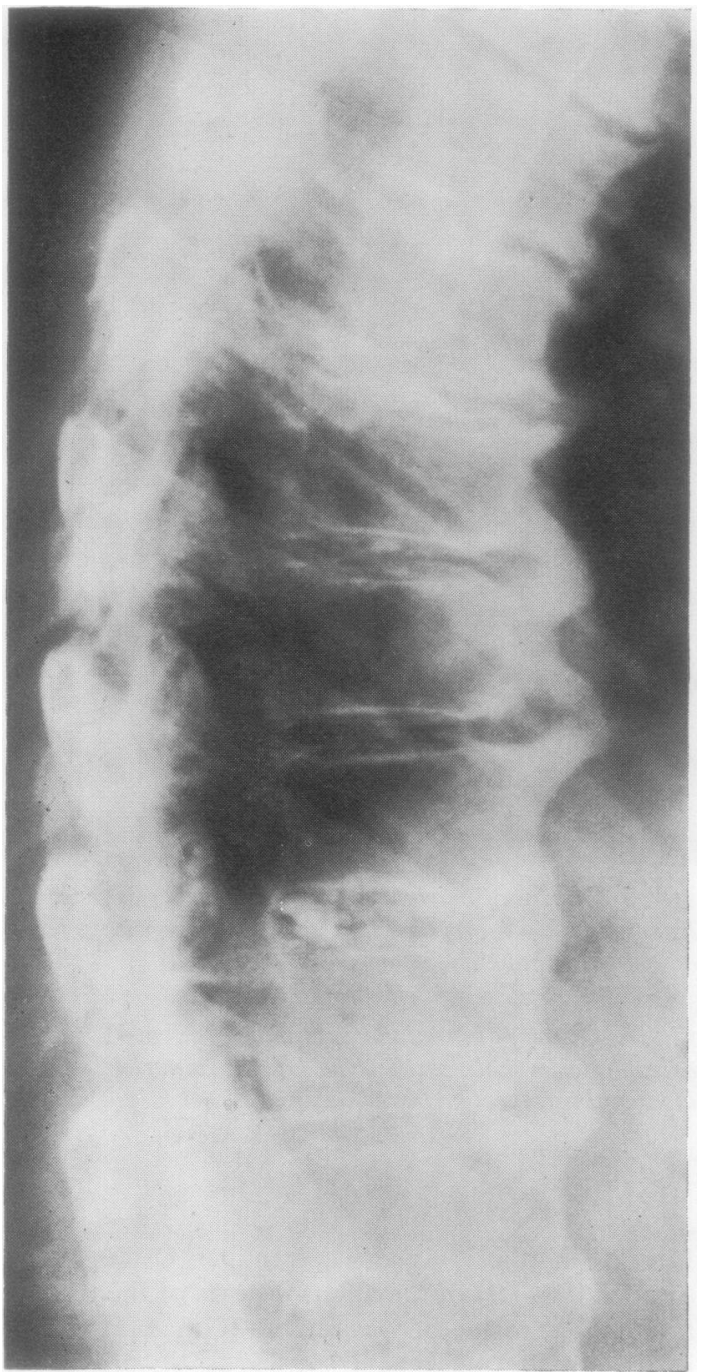

FIG. $7 \mathrm{X}$ ray of lateral thoracic spine, Patient B.A., showing calcified discs, kyphosis, and anterior coulée with bridging of discs and anterior vertebral body ossification. Note preservation of disc spaces.

\section{CORRELATION OF JOINT ABNORMALITIES WITH ACROMEGALY}

There was no clear correlation between backache, peripheral joint abnormalities, and the duration or severity of the acromegaly. However, very severe peripheral joint arthrosis (of hips and/or knees) was found in only four patients and they all had severe acromegaly of very long duration, refractory to treatment. Backache and gross radiological changes were recorded in five of the six patients considered cured. Most of the patients with anterior vertebral body ossification had severe disease of long duration. However, spinal hypermobility was found in many

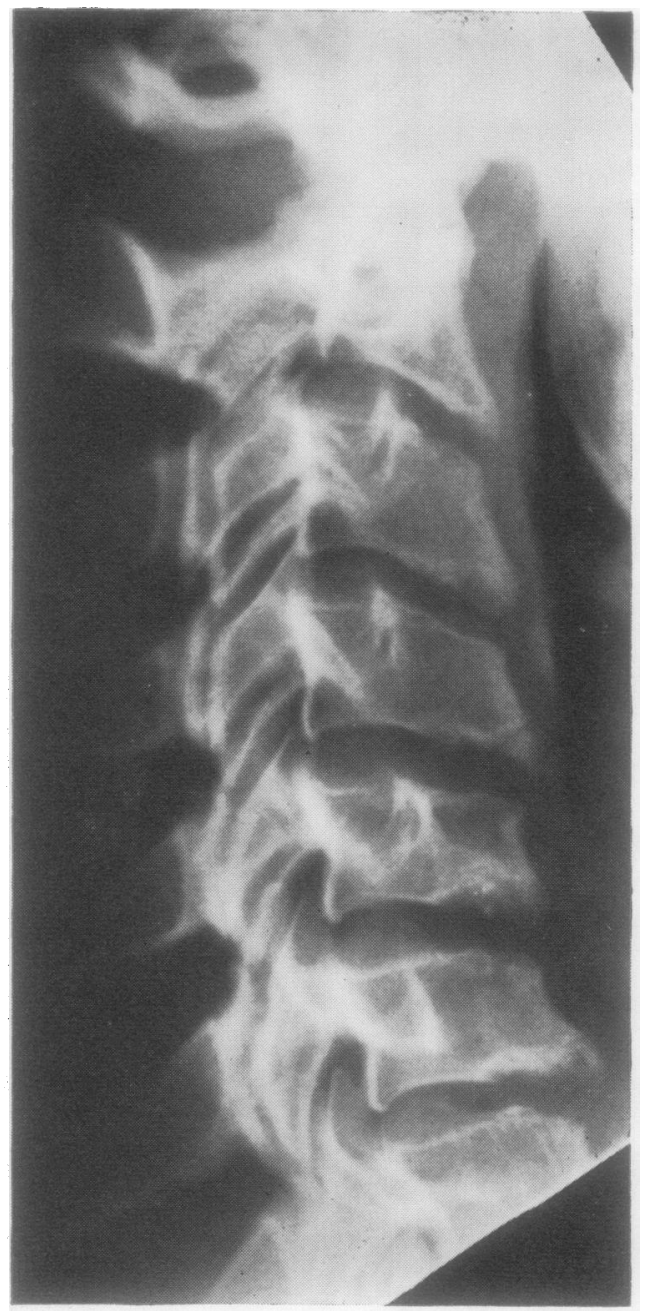

FIG. 8 X ray of lateral cervical spine, Patient 6, showing increased antero-posterior diameter of vertebral bodies due to new bone formation on their anterior aspects. Note irregularity of disc margins anteriorly.

patients irrespective of backache, radiological changes, or severity/duration of the acromegaly.

\section{MORPHOLOGY}

Morphological studies were conducted on joints obtained from three patients (two at necropsy, one at surgery).

Patient B.A. (not numbered in the Table) Male aged 48 years (at operation) with acromegalic facies since age 41 . Treated at age 43 by yttrium $^{90}$ pituitary implant with reduction in pituitary activity. 3 years later he began to feel pain in the right hip. $X$ ray showed bilateral osteoarthrosis for which Mr. George Arden performed a Charnley arthroplasty on the right hip. 


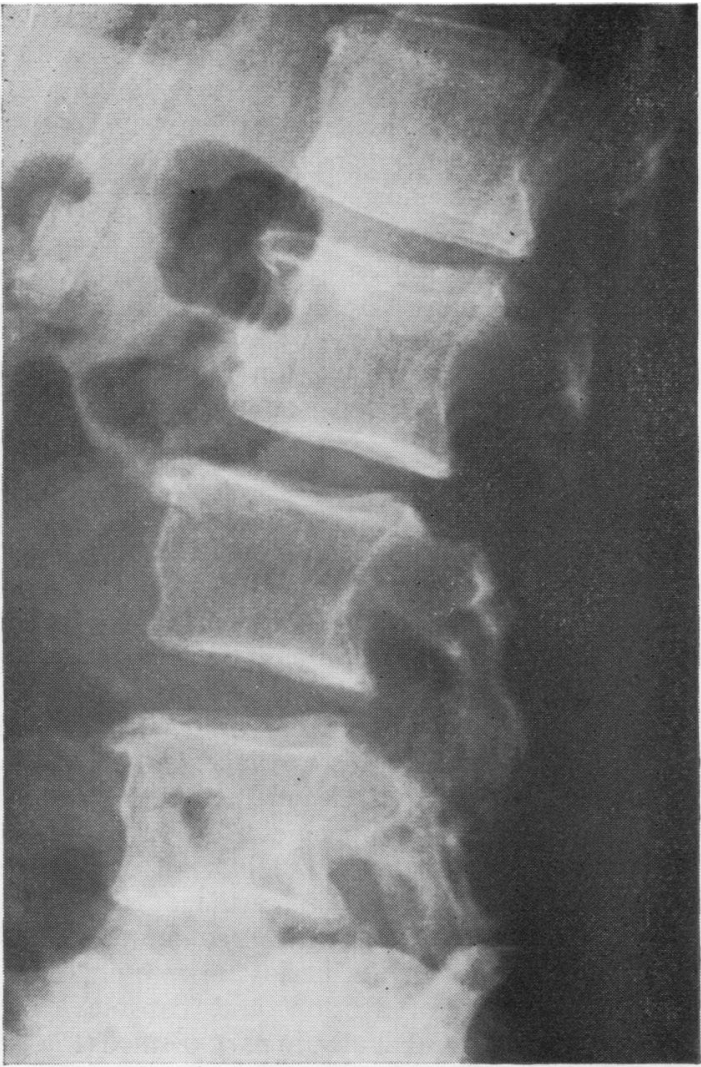

FIG. 9 X ray of lateral lumbar spine, Patient 41, showing increased posterior concavity with lumbar convexity. Grade II osteophytosis.

The removed femoral head showed gross degenerative and hypertrophic changes with eburnation down to bone on the superior and lateral weightbearing surface (Fig. 12a). This was characterized on section (Fig. 12b) by sclerosis and cyst formation together with luxuriant osteophyte formation (Fig. 12c) as well as by the death of superficiallyplaced bone cells and the proliferation of new metaplastic fibrocartilage and bone (Fig. 12d). This was particularly marked in areas of traumatic damage and reconstruction, occasioned by pressure of the acetabular margin. Both newly-formed regenerative fibrocartilage in such areas and original hyaline cartilage showed this chondrocyte proliferation and basophilia characteristic of growing tissue, even when it had been overlaid by new fibrous tissue or even bone.

Patient L.P. (not numbered in the Table) Female aged 59 at death, diagnosed 20 years before (at age 39) and treated by deep $x$ ray. In 1956 a partial gastrectomy for stomach cancer was performed, but she developed metastases from which she died 10 years later (1966).

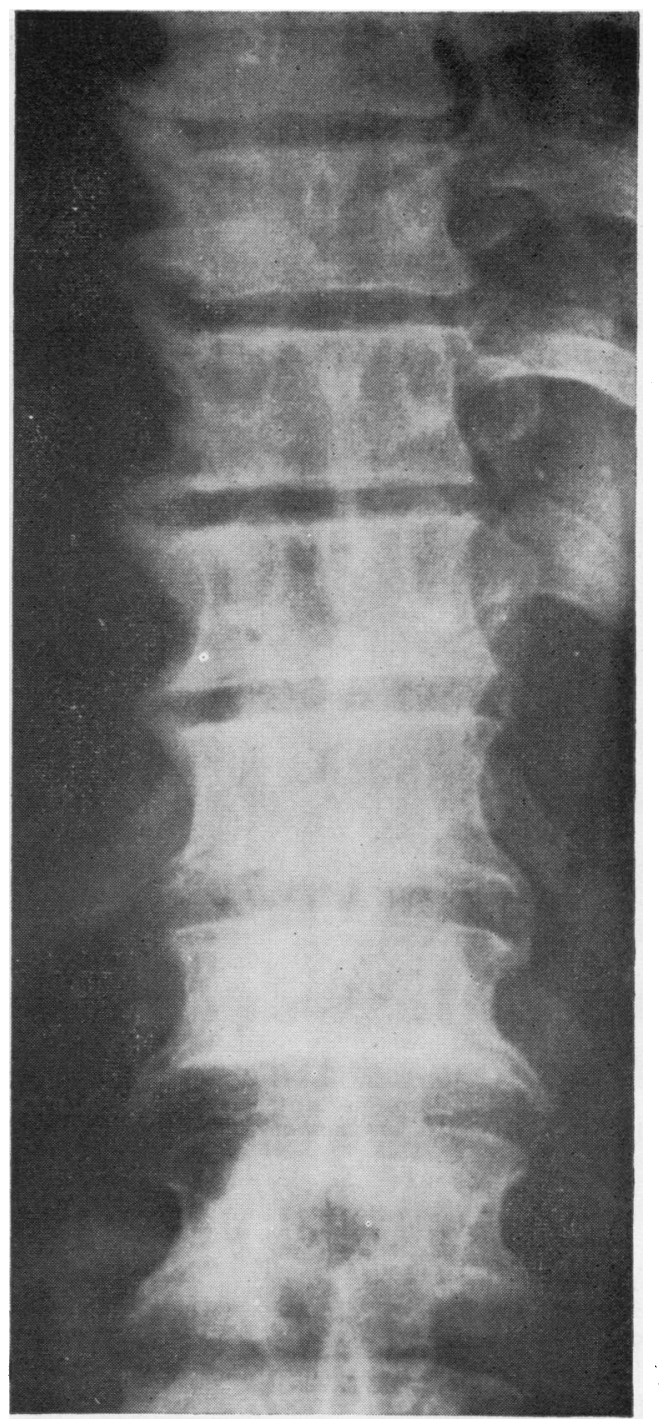

FIG. $10 \mathrm{X}$ ray of thoraco-lumbar spine, Patient 11, showing Grade III osteophytosis with retention of normal disc spaces.

She had pain in the left hip for two years but full movement.

The spine above T10-12 showed little disc degeneration but there was some narrowing and considerable protrusion with horizontally projecting osteophytic lipping at each disc space (Fig. 13a). Although in one area a small focus of calcinosis was seen (probably hydroxypatite because no crystal forms were seen in the decalcified spine), ossification did not spread into the anterior longitudinal ligament or back towards the middle of the vertebral body as in the advanced states of hyperostosis and as figured in the advanced stages 


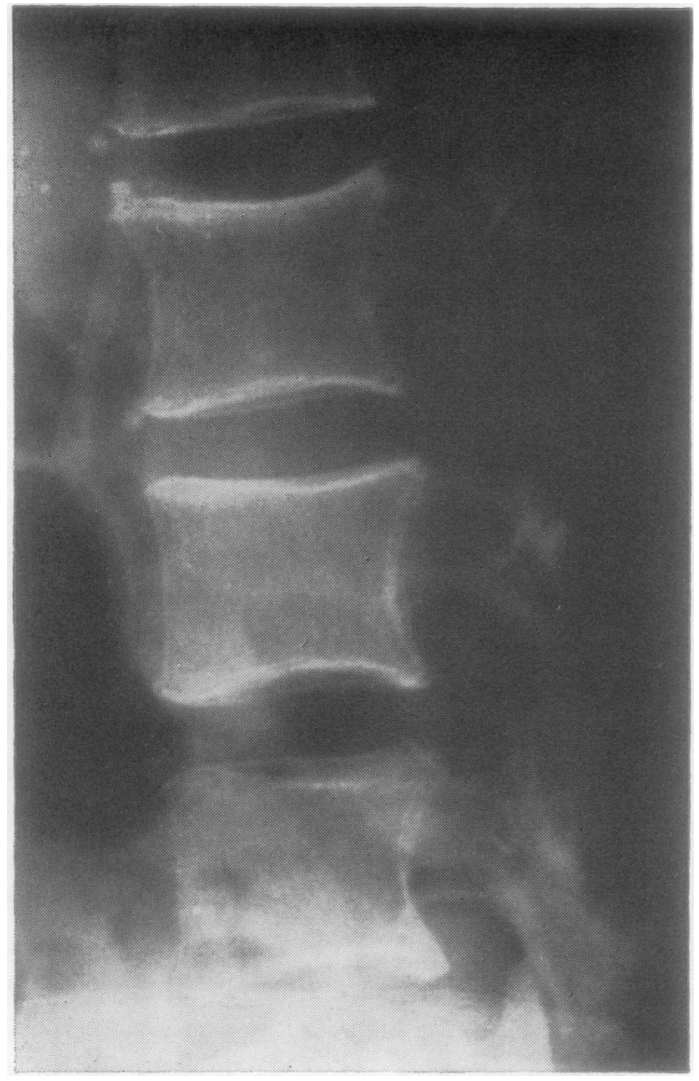

FIG. $11 \mathrm{X}$ ray of lateral lumbar spine, Patient 27, showing calcified areas at anterior margins of discs.

of acromegaly by Erdheim (1931). At the interspace between $\mathrm{T} 11$ and T12, gross disruption of the basal plate was seen unlike that occurring in degenerative change because of the enormous irregular proliferation of cartilage, highly tasophilic, in the marrow spaces (Fig. 13b).

The femoral head showed proliferative cartilage ch anges with minor osteophyte formation laterally and medially. Cartilage was of good thickness but showed evidence of local proliferation, especially in weight-bearing areas. No bone exposure was seen. By contrast, the shoulder cartilage was worn thin and the underlying bone sclerosed (Fig. 13c). Marginal cartilage overgrowth resulting in osteophyte formation showed chondrocyte proliferation, pericellular ground substance accretion, and fissuring. Fissuring, seen here and in other cases, was thought to be real and not artefactual because of the occurrence of fibrinous material within the fissures.

The knee joint showed a general thickening of articular cartilage (shown grossly (Fig. 13d) and microscopically (Fig. 13e) to be mainly a midzone and basal basophilic proliferation with comparatively slight surface fibrillation), together with a large. pressure cyst in the intercondylar region. A large? undercut ulcer was present in the weight-bearing area of the medial condyle (Fig. 13f). Fig. $13 g$ shows that there was no underlying bone reaction.

Case 23. Female aged 68 at death with pains in the finger joints and other features of acromegaly for 5 years not previously diagnosed and without treatment. Breathlessness for 6 weeks was due to adenocarcinoma of the bronchus from which she died.

The superior cartilage surface of the femoral heade showed an area of ragged ulceration (Fig. 14a) and sections show this to be confined to cartilage and with undermined edges: underlying bone showed no sclerosis (Fig. 14b). The cartilage in all joints showed cellular overgrowth with intense metachromasia ando this affected the deeper layers of cells. The lumbar? spine showed discs of greater than normal height with healthy hypertrophic cartilage. On the anterioe edge of one, there was a small area of calcinosis corresponding to the opacities seen on $x$ ray (Fig. 14c). The interphalangeal joints of the fingers showed similar changes in cartilage and markedo marginal osteophytes with proliferative fibro-s cartilage changes at the periosteal margin, and ato the attachment of tendon and capsule, whicho became calcified and finally, in part, ossified (Fig. $3 b) \stackrel{\mathbb{Q}}{\varrho}$

The knee showed osteoarthrotic changes with $\overrightarrow{\vec{b}}$ eburnation and grooving and, in places, ulcer 3 formation with fibrillation of cartilage (Fig. 14d) $\stackrel{?}{?}$ These changes were different from those of de? generative joint disease only in as far as the deepero cartilage cells were grossly hypertrophic and surrounded by areas of basophil ground substance accretion. However, superficial cartilage cells were very small and appeared to be replicating especially? in the fissures produced. The patella showed fibrocartilage overgrowth at the upper pole and in areas this had become calcified with small areas of ossification (Fig. 14e, overleaf). The articular surfaceof the patella showed thickened cartilage in its $N$ upper part and eburnation down to bone in its lower portion.

\section{Discussion}

This study has confirmed the frequent occurrence? of locomotor system disorders resulting from acromegaly (Kellgren and others, 1952). Peripheral joint pain and backache were the outstanding@ symptoms. Although objective joint signs were $\mathbb{Q}$ detected in 26 out of the 42 patients examined, joint swelling was found in only nine patients, and only in two of these were there synovial effusions;응 
12(a)

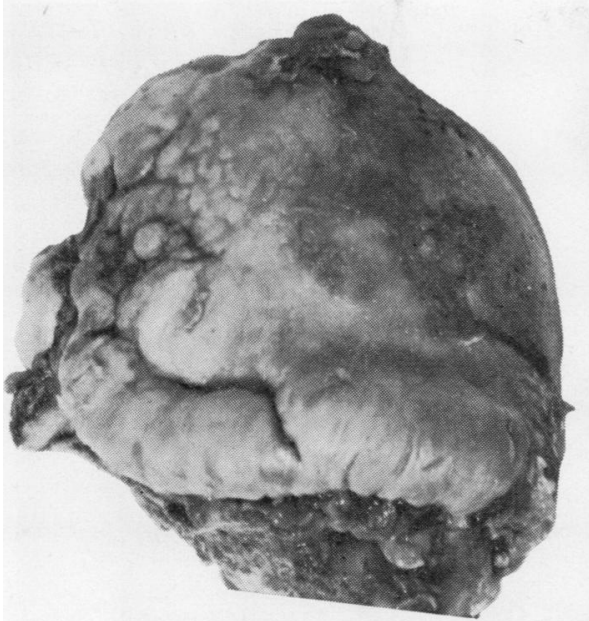

12(b)

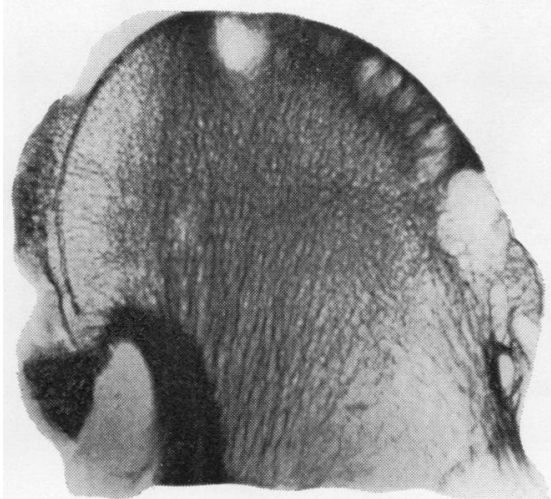

12(d)

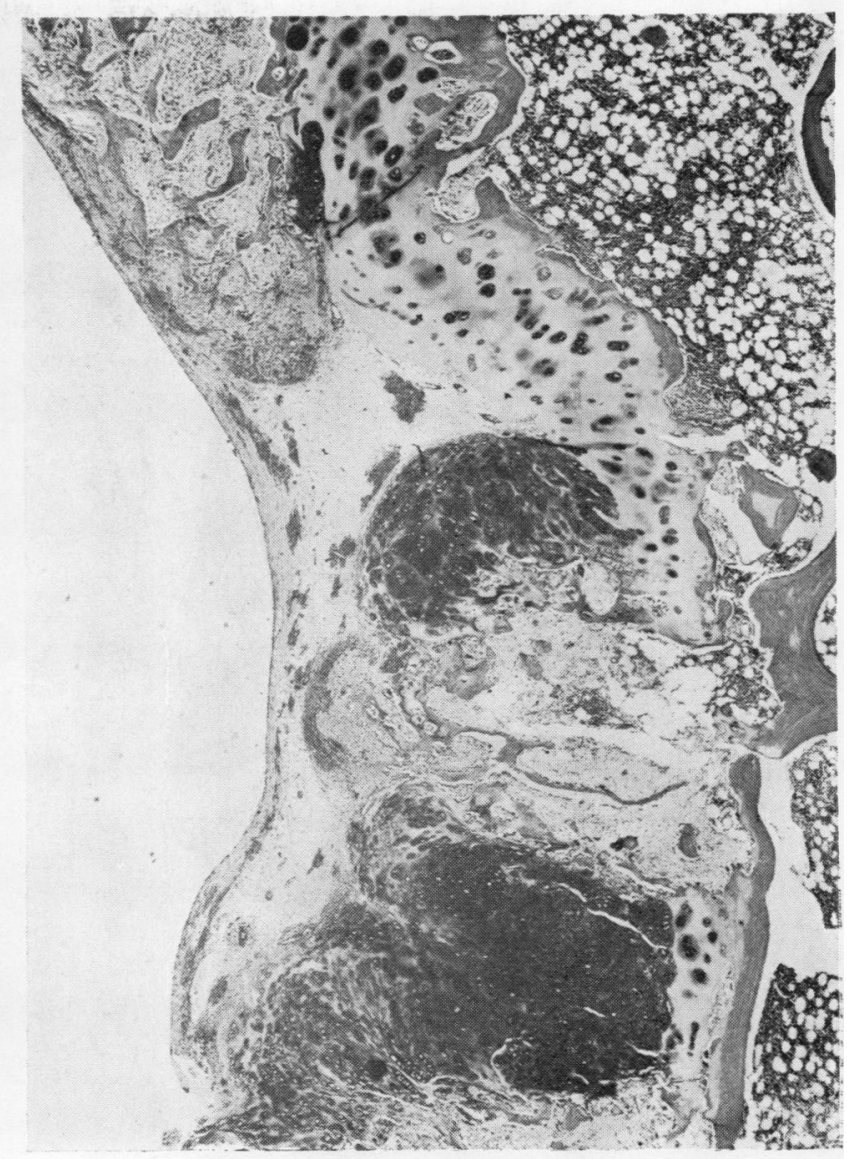

FIG. 12 Patient B.A.

(a) Excised femoral head; showing degenerative changes, hypertrophied cartilage, and eburnation.

(b) X ray of sectioned femoral head.

(c) Histology of femoral head, showing sclerosis, cyst formation and osteophytes.

(d) Coronal high-power view of lower joint surface in Fig. 12(c) (arrow), showing hyaline-like cartilage regenerating from original remnants and new bone formation. Haematoxylin and eosin. $\times 18$.

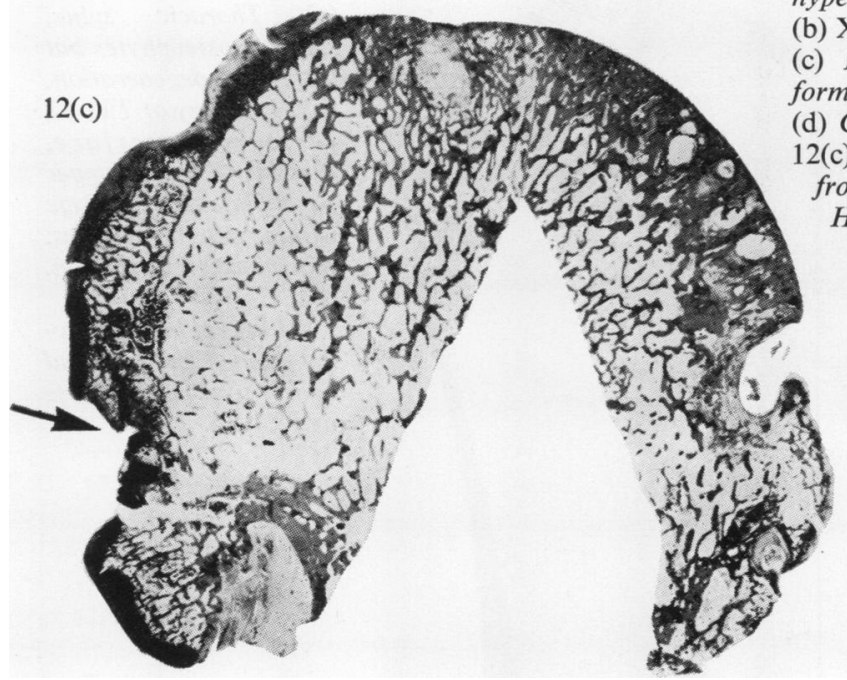



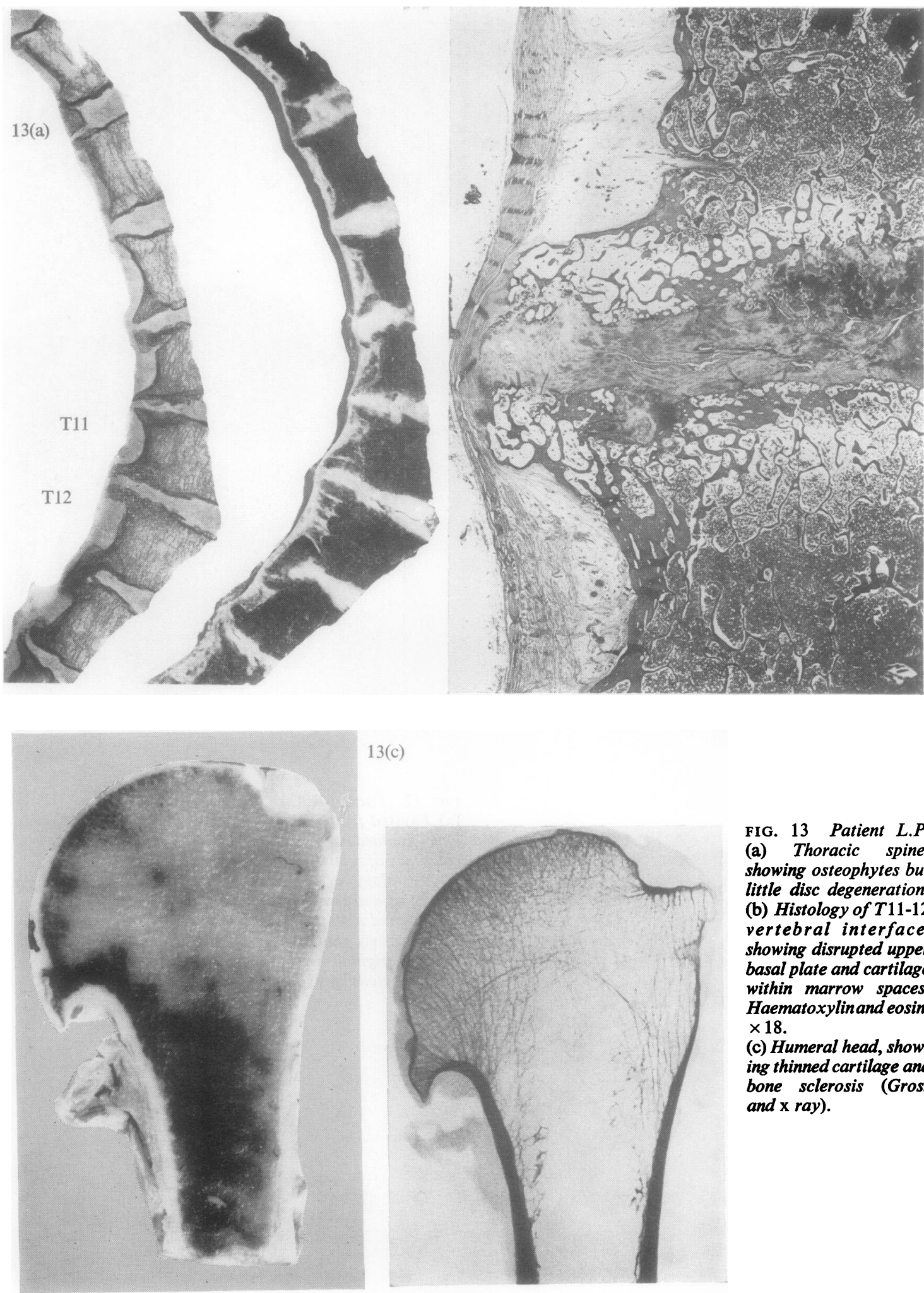

13(c)

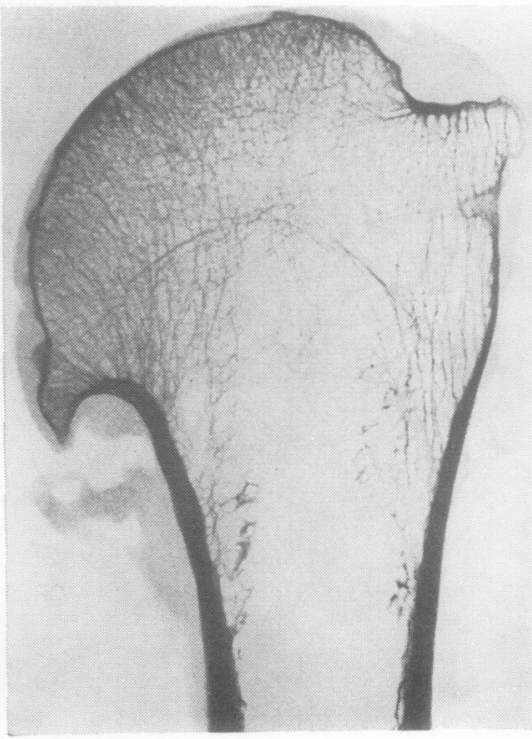

FIG. 13 Patient L.P. (a) Thoracic spine, showing osteophytes but little disc degeneration. (b) Histology of T11-12 vertebral interface, showing disrupted upper basal plate and cartilage within marrow spaces. Haematoxylinand eosin. $\times 18$.

(c) Humeral head, showing thinned cartilage and bone sclerosis (Gross and $\mathrm{x}$ ray). 
13(d)
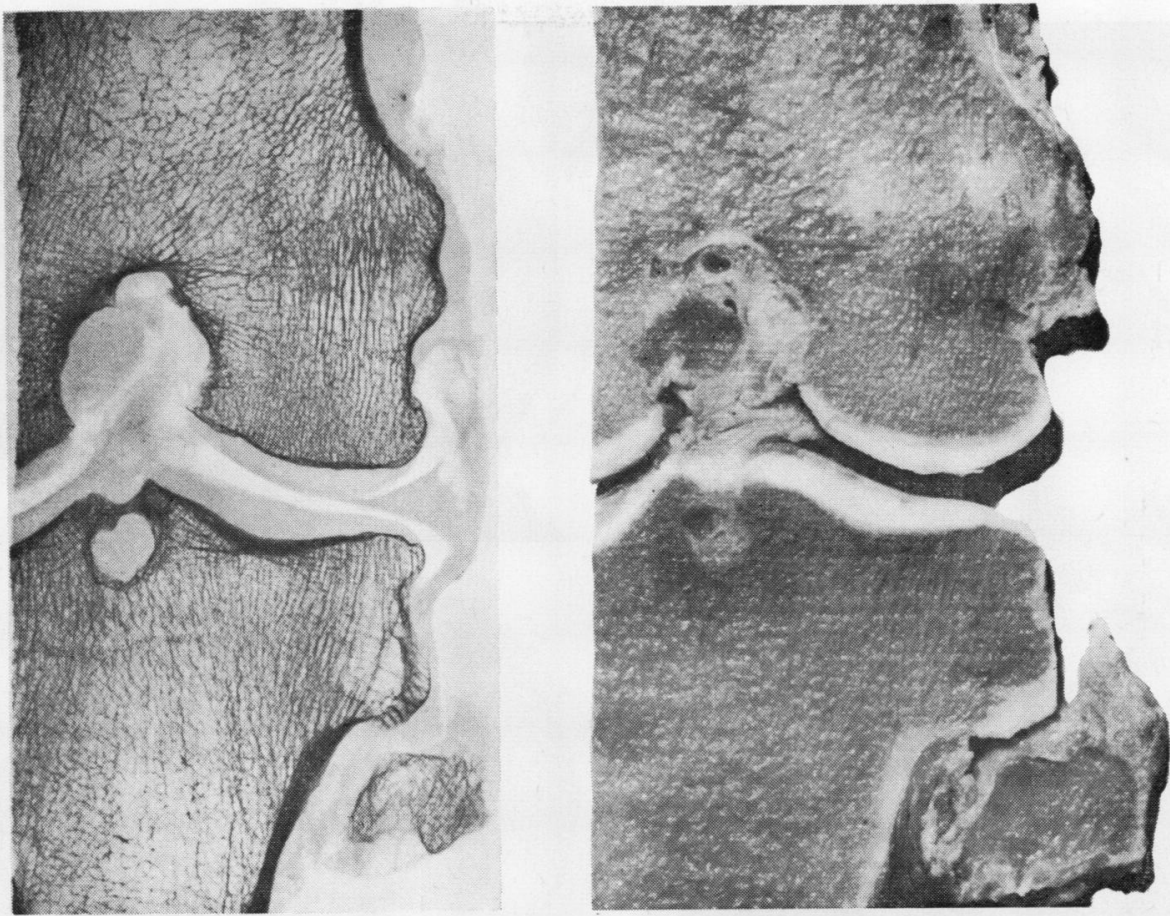

13(d) Section and $\mathrm{x}$ ray of knee joint, showing thickened articular cartilage and tibial cyst.

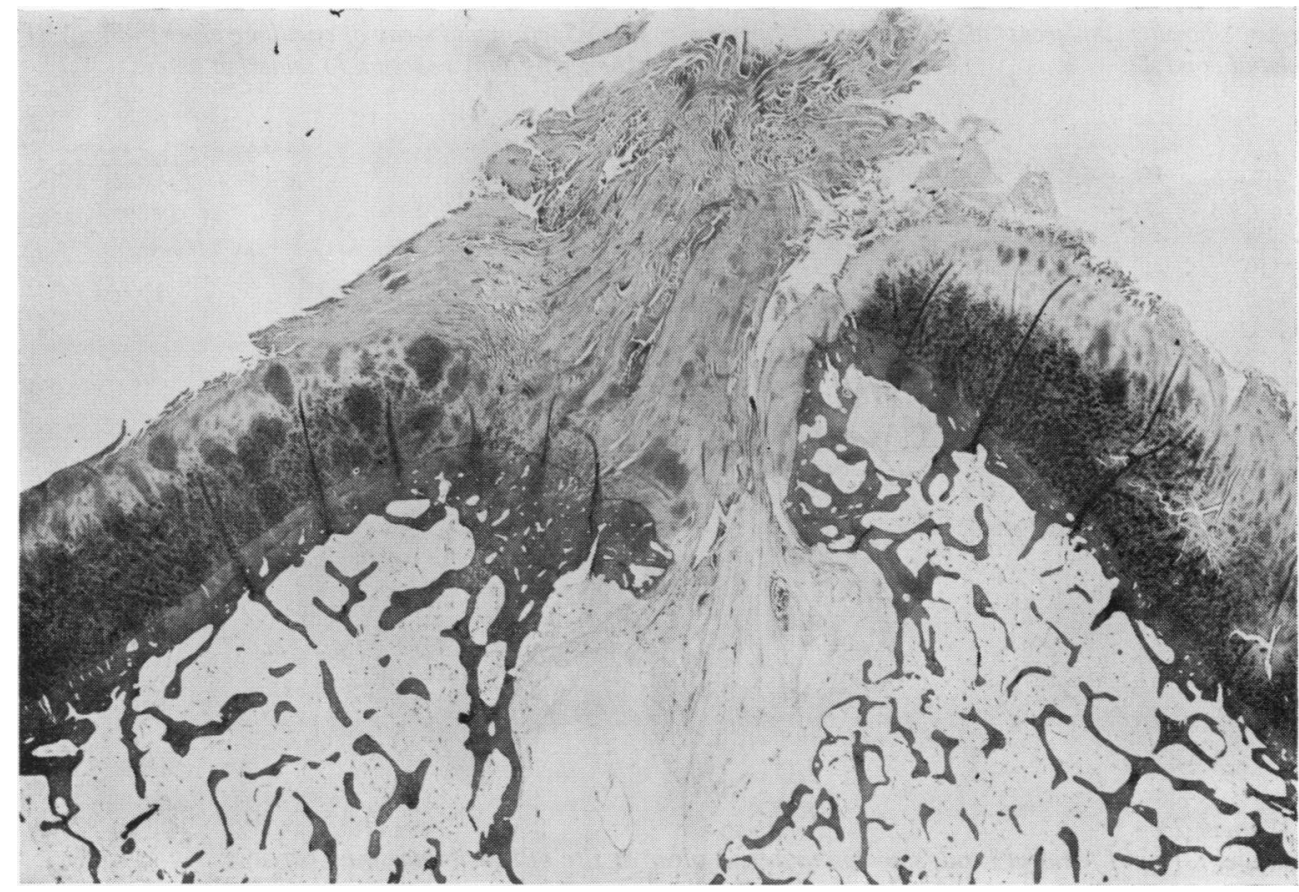

13(e) Histology of upper tibial crticular surface, showing inid-zone basophilic proliferation and intercondylar cyst formation. Haematoxylin and eosin. $\times 6$. 
13(f) Femur, showing undercut ulcer on weight-bearing

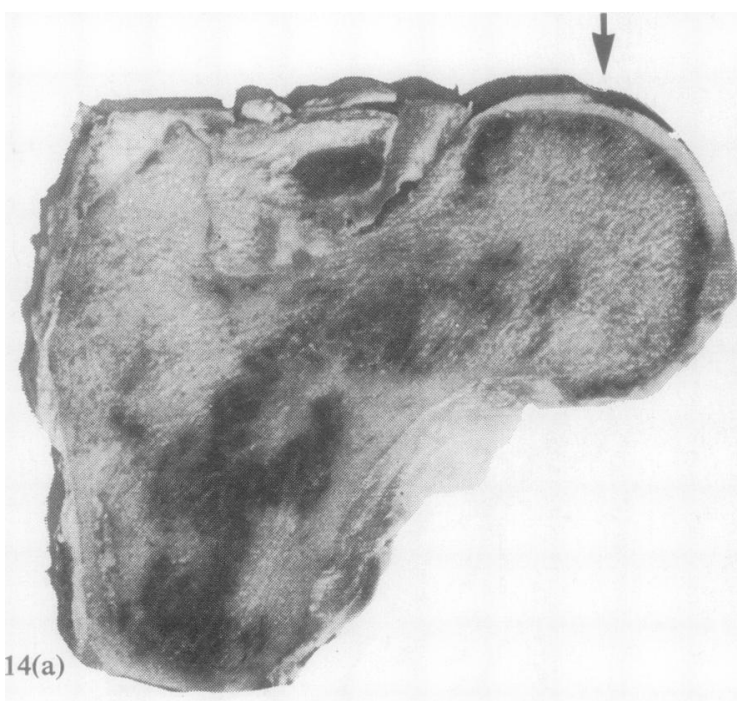
area of medial condyle.
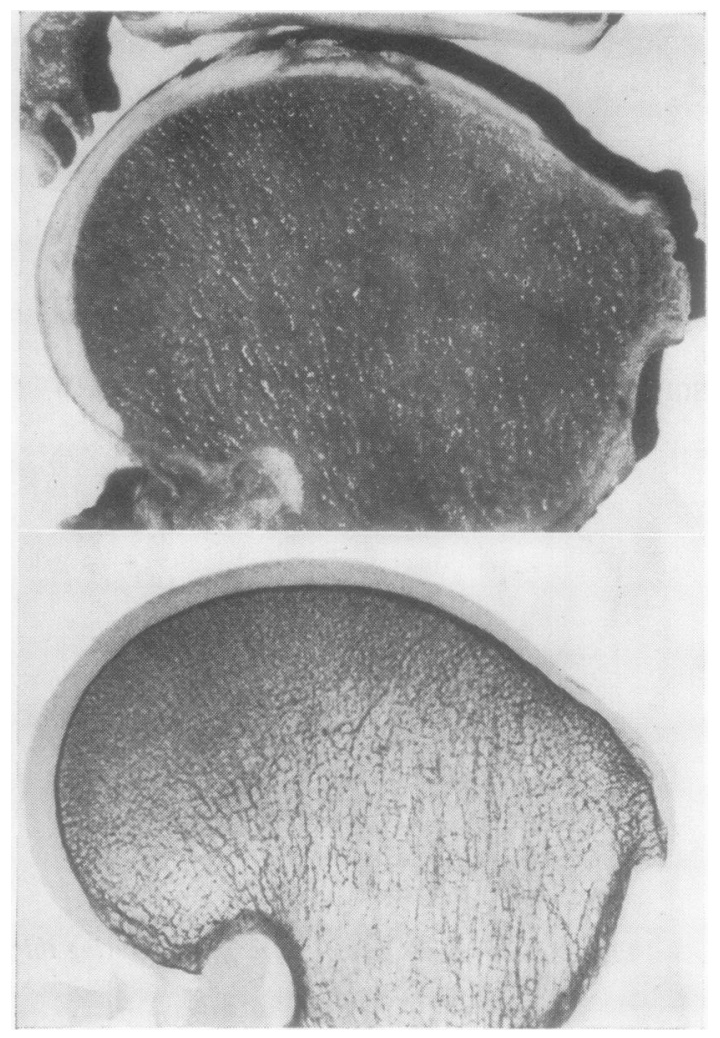

13(g) Section and $\mathrm{x}$ ray of cartilage ulcer in Fig. 13(f). Note absence of bony reaction to undercut ulcer.

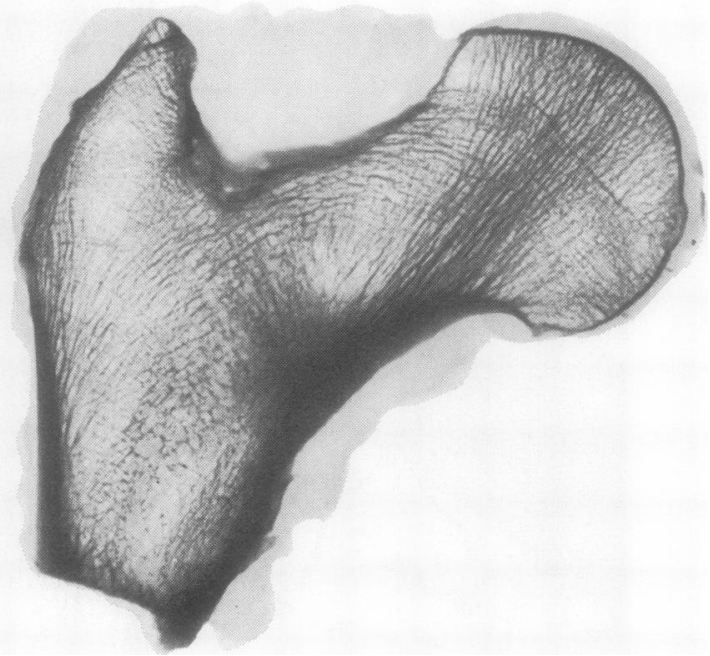

FIG. 14 Patient 23

(a) Section and $\mathrm{x}$ ray of femoral head, showing undercut ulcer at site of maximum stress (arrow).

(c) Section, $\mathrm{x}$ ray, and histology of anterior edge of lumbar spine, showing areas of calcinosis (arrow). Haematoxylin and eosin $\times 40$. (b) Histology of femoral head ulcer arrowed in Fig. 14(a), showing undermining and absence of underlying bone sclerosis. Haematoxylin and eosin $\times 12$. 


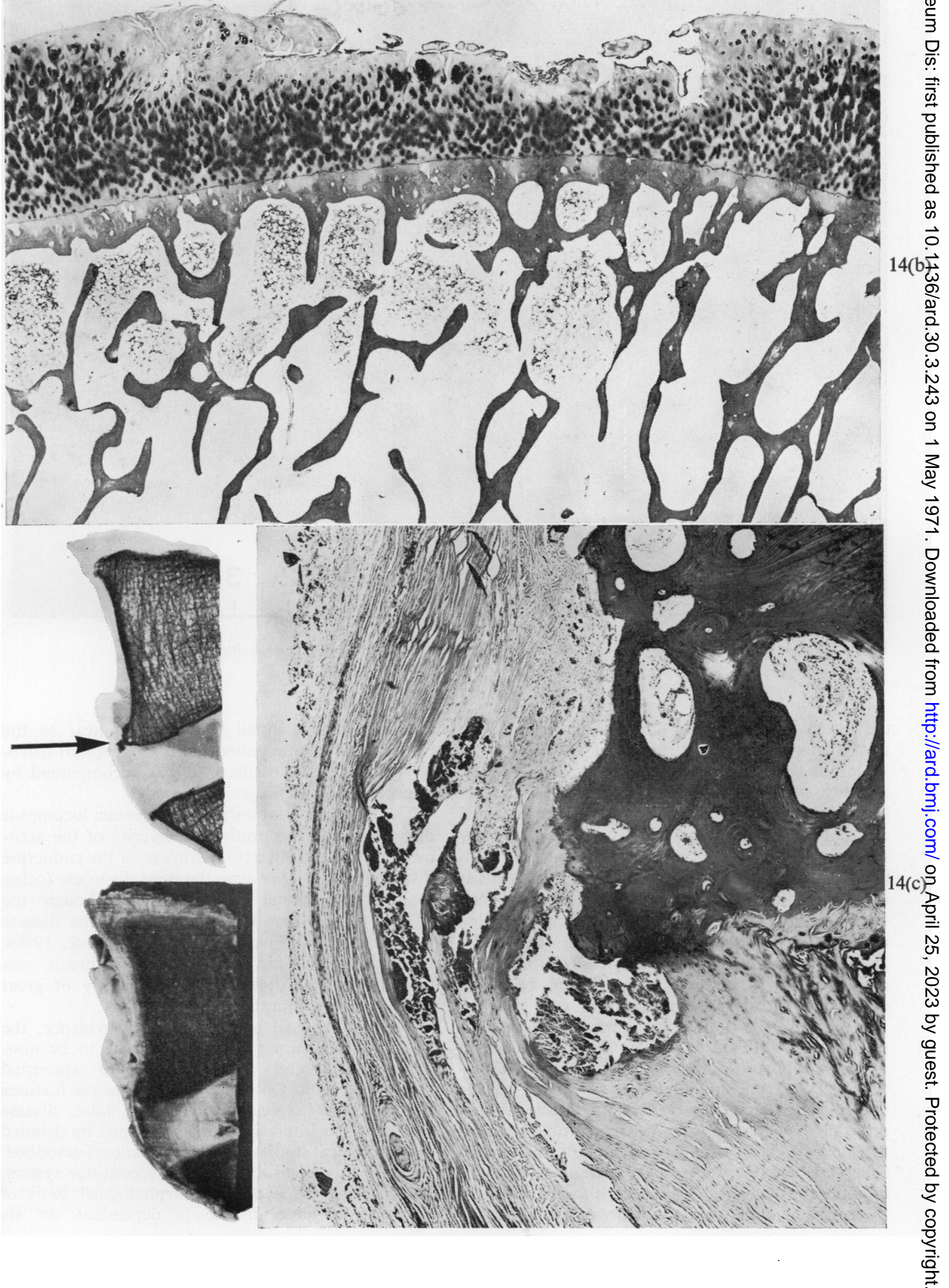




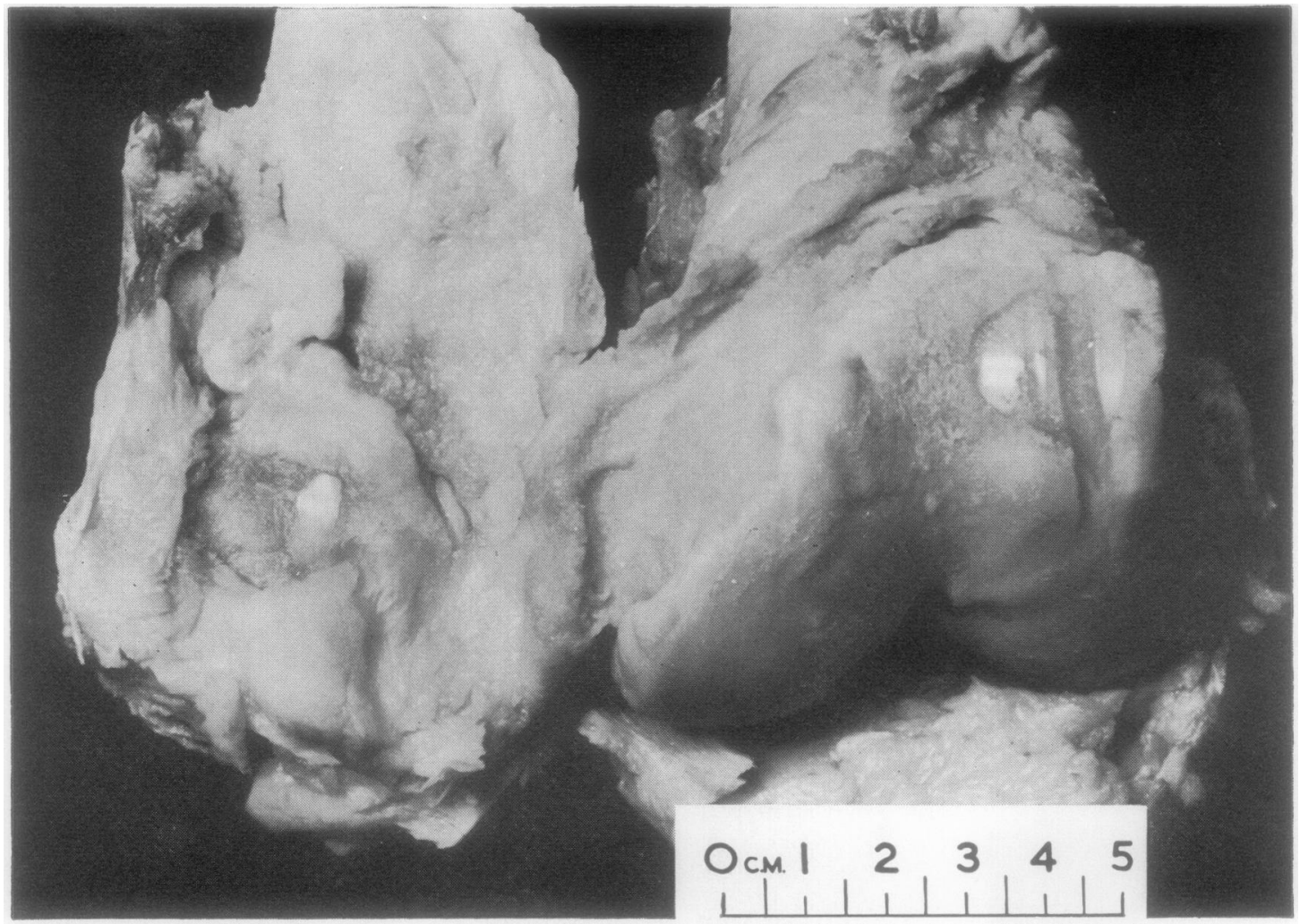

14(d) Articular surfaces of femoral condyles and patella, showing eburnation with grooving.

the others appeared to have noninflammatory thickened synovial and periarticular tissues.

Despite the frequency of backache as a symptom, together with gross spinal changes seen radiologically, back movement was well maintained and often greater than normal. This was particularly striking in some older patients and contrasts with degenerative spondylosis where spinal movement is usually restricted. It is probable that the thickened intervertebral disc cartilages, together with lax hypertrophied paraspinal ligaments, contribute to the increased spinal mobility. Indeed, this excess mobility may itself predispose to the backache and osteophytosis so prominent in our patients.

In general, the radiological appearances of peripheral joints differed little from those described in previous reports (Steinbach, Feldman, and Goldberg, 1959; Lang and Bessler, 1961). The grossly thickened cartilage, often with marginal osteophytes, presumably accounts for the remarkable crepitus detected on knee and shoulder joint movement. Several patients showed $x$-ray appearances suggestive of chondrocalcinosis of the knees, although episodes of crystal synovitis did not occur. A small focus of calcification was noted histologically near to the lumbar disc of one patient, and gross spinal osteophytosis and disc ossification was accompanied by thickened disc cartilages.

There was no clear correlation between locomotor disorders and the duration or severity of the acromegaly. Nor did effective treatment of the endocrine disease necessarily reverse the joint disorders (other than carpal tunnel compression), although the effectiveness of treatment in arresting the disease is very variable (Roth, Gorden, and Brace, 1970). However, gross hip and/or knee arthrosis was found only in patients with acromegaly of great severity or long duration.

Thus on clinical and radiological evidence, the arthrosis in acromegaly would appear to be noninflammatory and due probably to abnormal cartilage growth. Only later do some of the features of the more typical degenerative joint disease develop. This impression was confirmed by detailed morphological studies in the three patients described. Because pathologists neglect the locomotor system, present knowledge of the morphological basis of acromegalic joint disease is dependent on six 


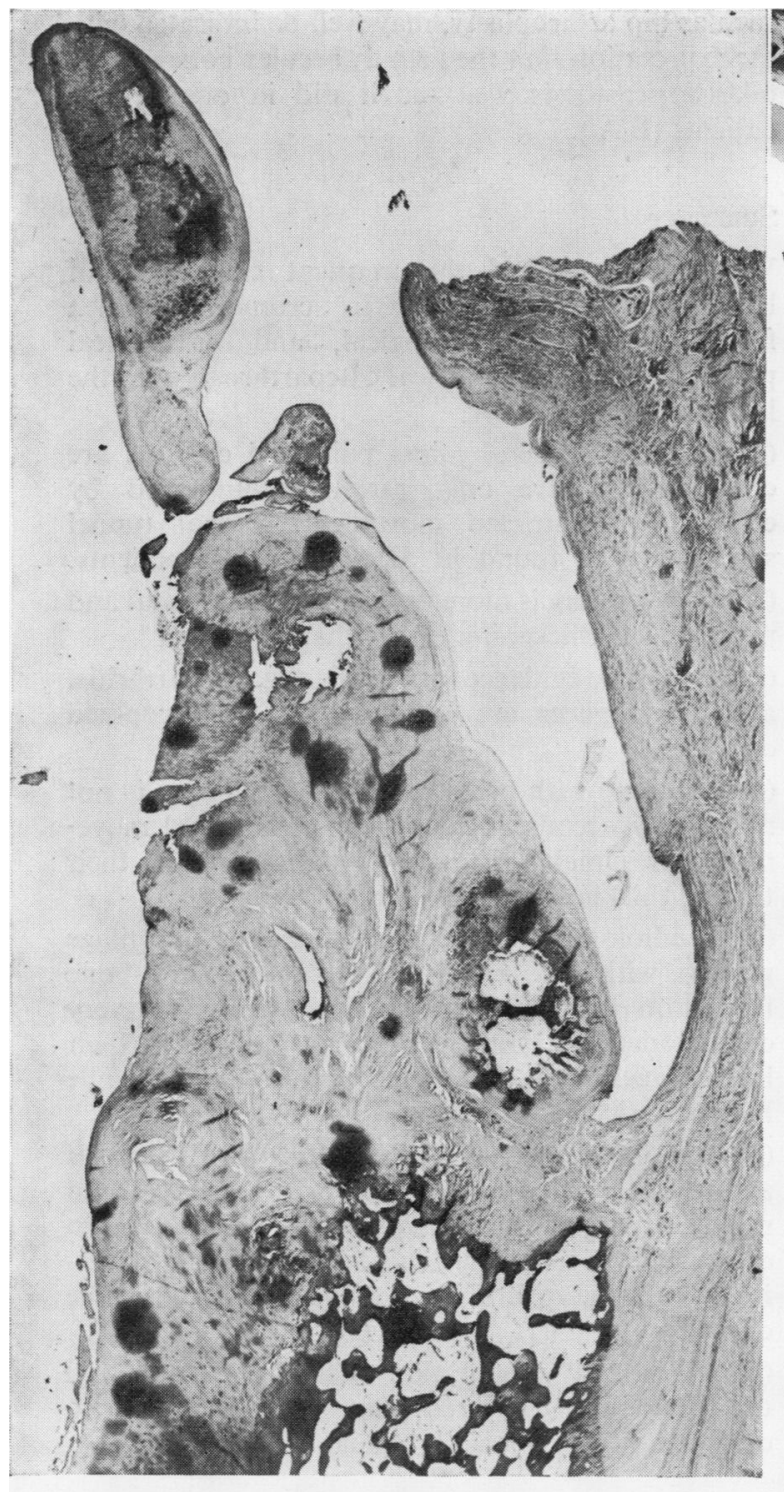

autopsied cases described in four publications:

Erdheim (1931) one case,

Waine and others (1945) one case including toe, spine, knee, and ribs,

Kellgren and others (1952) three necropsy cases, the knee and fifth toe on one, the big toe of another, and soft tissues from the third, as well as biopsy specimens from six other cases.

Remagen (1965) bone and cartilage changes in the shoulders, hips and left knee joint in a woman aged 64 years who died after surgical removal of a pituitary adenoma.

The present study adds to this very limited world material observations on the joints in three cases, viz. - a resected femoral head from one treated

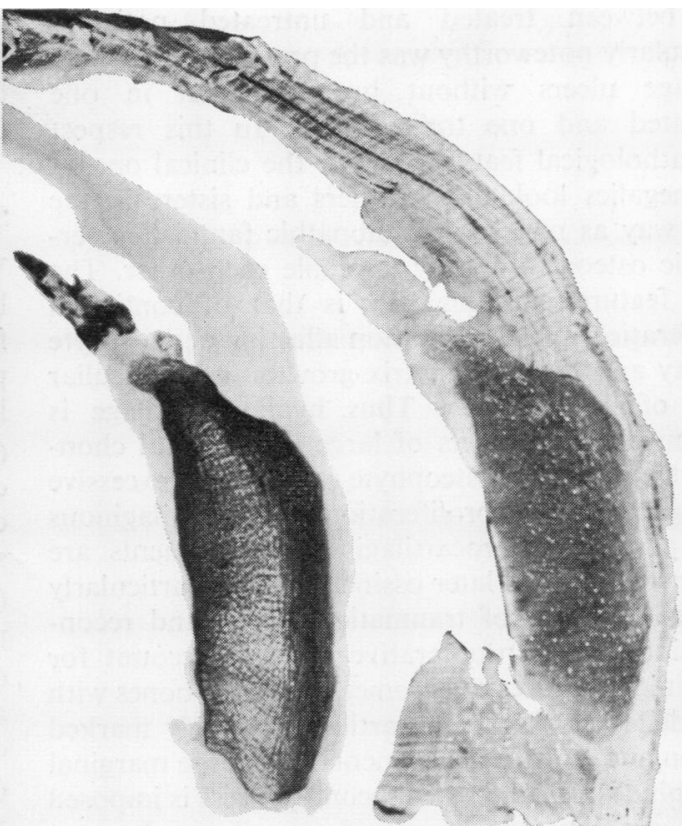

14(e) Sagittal section, $\mathrm{x}$ ray, and histology of patella, showing thickened cartilage in its upper part and eburnation of its lower portion. Note fibrocartilaginous spur at upper pole containing areas of ossification and calcified fibrocartilage. Haematoxylin and eosin $\times 7$.

case, and autopsy material, including hip, spine, and shoulder, knee joint, and finger from two other cases, one treated and one untreated.

Our findings confirm in general the classical description of Kellgren and others (1952); their description of bone and cartilage change was, however, mainly concerned with the knee of an early active and untreated case (case 26 aged 34 at death 5 years after onset of symptons). This present study describes the adaptive changes found in the joints of three older patients whose disease had lasted respectively 5,7 , and 20 years as a minimum; the patient with symptoms for 5 years was untreated. These changes consisted of both degenerative and regenerative processes occurring in abnormally growth stimulated cartilage. There was abnormally developed bony replacement of hypertrophic hyaline cartilage, very active remodelling of bone, development of fibrocartilaginous regenerative changes in the marginal areas, classical acromegalic ulcers, and the supervention of degenerative changes. This degenerative change is paradoxical as it occurs because of the unnatural youthful vigour of the cartilage cell, well known from macerated specimens.

Reviewing the clinical findings in the light of radiological changes and interpreting the latter in terms of the morphological changes found in three patients, it is surprising that there was so little difference between the subjects aged 48,59 , and 68 , 
and between treated and untreated patients; particularly noteworthy was the presence of classical cartilage ulcers without bone reaction in one untreated and one treated case. In this respect the pathological features mirror the clinical onesacromegalics look like brothers and sisters in the same way as males with idiopathic familial hypertrophic osteoarthropathy resemble each other. The main feature pathologically is that of continued proliferation and regeneration affecting chondrocyte activity and cartilage matrix growth and a peculiar form of degeneration. Thus hyaline cartilage is thickened with clusters of large active basal chondrocytes; marginal osteophyte formation is excessive through exuberant proliferation of the cartilaginous cap; periosteal fibrocartilaginous attachments are hypertrophied and later ossified. This is particularly marked in areas of traumatic damage and reconstruction. These proliferative changes account for the clinical features of acromegaly-large bones with remodelled shafts, thick cartilage, strongly marked tendon and capsule attachments, and large marginal osteophytes. In addition a second process is imposed - the development of specific cartilage ulcers at weight-bearing sites, presumably because of unequal cell proliferation and matrix formation in the midzone, creating stress in the inter-territorial areas and ultimately fissuring. These ulcers, despite cartilage youthfulness (and indeed because of it) lead on to the third stage of degenerative change with loss of substance. But this is degenerative change with a difference. Firstly, it is localized, and secondly the reparative process appears to be abnormally increased. Usually, in degenerative joint disease or the advanced state of severe rheumatoid arthritis, reparative processes ensure the production of fibrocartilage plugs. But in acromegaly this newformed regenerating fibrocartilage is excessive and striking, forming a layer covering the old hyaline cartilage on the exposed bone.

Finally, irreversible and incapacitating degenerative joint disease with eburnation and cysts may become the outstanding feature of acromegaly and should be treated on its own merit. Surgery, such as hip arthroplasty, may well be indicated with the expectation that the firm trabecular bone should take a prosthesis well-as it did in one of our patients (B.A.).

\section{Summary}

We have confirmed the frequent occurrence of locomotor system disorders in acromegaly, which form a clinical, radiological, and histological picture differing from typical osteoarthrosis until the last stages of evolution.

(1) In the peripheral joints pain and crepitus are common but are only rarely accompanied by effusion or restricted movement. Carpal tunnel syndrome was found in 52 per cent. of patients.

(2) Joint swelling is more usually due to synovial and periarticular thickening rather than effusion.

(3) There is no evidence for an inflammatory arthritis, and joint spaces are increased by hypertrophied cartilage.

(4) Backache with gross radiological changes is not necessarily accompanied by impaired spinal movement-presumably because the discs retain their turgor, thickness, and resilience.

(5) Radiologically, there is increased cartilage growth with thickening and increased new-bone formation with remodelling. This affects in a very characteristic fashion the vertebral bodies: in their later stages they resemble those seen in senile hyperostotic spondylosis.

(6) Histologically, the characteristic feature is active cartilage cell proliferation in the basal and middle layers of the cartilage, presumably through excess growth hormone. This leads to the characteristic ulceration of Erdheim and later to degenerative changes.

(7) The severity or duration of the acromegaly and the effectiveness of treatment does not seem to correlate with the joint or spinal changes.

We wish to thank Professor Russell Fraser for allowing us to study his patients.

\section{References}

ERDHEIM, J. (1931) In 'Pathologie und Klinik in Einseldarstellungen', ed. L. Aschoff, H. Elias, H. Eppinger, C. Sternberg, and K. F. Wenckebach, vol. 3. Springer, Berlin.

Kellgren, J. H., Ball, J., AND Tutron, G. K. (1952) Quart. J. Med., 21, 405 (The articular and other limb changes in acromegaly).

LANG, E. K., AND BESSLER, W. T. (1961) Amer. J. Roentgenol., 86, 321 (The roentgenologic features of acromegaly).

MARIE, P. (1886) Rev. Méd. (Paris), 6, 297 (Sur deux cas d'acromégalie).

Remagen, W. (1965) Virchows Arch. Path. Anat., 340, 8 (Neue Befunde bei Akromegalie und nachfolgender Arthrose).

Roth, J., GoRDEN, P., AND BRACE, K. (1970) New Engl. J. Med., 282, 1385 (Efficacy of conventional pituitary irradiation in acromegaly).

Strinbach, H. L., Feldman, R., AND GoldberG, M. B. (1969) Radiology, 72, 535 (Acromegaly).

WAINE, H., BENNETt, G. A., AND BAUER, W. (1945) Amer. J. med. Sci., 209, 671 (Joint disease associated with acromegaly). 